\title{
Propranolol concentrations in plasma after insertion into the vagina
}

\author{
L G PATEL, S J WARRINGTON, R M PEARSON
}

\begin{abstract}
Six healthy women participated in a study of the concentrations of propranolol achieved in plasma after insertion of the drug into the vagina. In four of the women the concentrations were also determined after administration by mouth. The area under the concentration curve for propranolol administered per vaginam was significantly greater than that after oral administration. There were small significant reductions in systolic blood pressure, pulse rate, and forced expiratory volume in one second after vaginal administration but these did not cause any symptomatic side effects.

The tolerability of the vagina to drugs and the safety of this form of treatment remain to be determined. Probably further studies of the contraceptive effects of propranolol should be conducted with the dextro isomer of the drug.
\end{abstract}

\section{Introduction}

Novel, safe, and effective methods of contraception are needed. Spermicides are among the oldest forms of chemical contraception and have the advantage that they do not depend on highly skilled professionals for their prescription and use ${ }^{1}$; they have, however, been limited by poor efficacy.

Propranolol is a potent inhibitor of human sperm motility in vitro $^{23}$ and has a similar effect in vivo in rats. ${ }^{4}$ This gives the drug a potential for use as a vaginal contraceptive or for incorporation in an intrauterine contraceptive drug delivery system. ${ }^{4}$ Clinical studies $^{5}$ show a pregnancy rate of between three and four per 100 women years when conventional $80 \mathrm{mg}$ propranolol tablets are inserted into the vagina on each evening of the cycle from the last day of menstruation until the first day of the next cycle. In evaluating the safety of spermicides it is important to examine the concentrations achieved in plasma after placement in the vagina and the potential systemic side effects in addition to any local reactions.' Since propranolol administered by mouth or intravenously may cause symptoms such as wheezing in some subjects, we examined the systemic and clinical effects of propranolol after administration into the vagina and compared the concentrations achieved in plasma with those after oral administration.

\section{Subjects and methods}

Six healthy non-pregnant women who were accustomed to using tampons were selected for study. Informed consent was obtained from all. Their ages ranged from 20 to 29 (mean 24) years and weight from

Department of Clinical Pharmacology, St Bartholomew's Hospital, London EC1A 7BE

L G PATEL, BSC, research assistant

R M PEARSON, MRCP, senior lecturer, hon consultant physician

Charterhouse Clinical Research Unit, London EC1

$S$ J WARRINGTON, MRCP, director

Correspondence and requests for reprints to: $\operatorname{Dr} \mathrm{R} M$ Pearson.
57 to 74 (mean 62) kg. All were screened for cardiovascular, respiratory, renal, hepatic, and gynaecological disease and diabetes mellitus by symptom questionnaire, physical examination, blood and urine tests, electrocardiography, and vitalography. All were protected against pregnancy by using an oral contraceptive or an intrauterine contraceptive device. The study was performed during days 1 to 21 of the menstrual cycle. On the day of the study the subjects attended fasting and an intravenous cannula was inserted into a left antecubital vein. A $6 \mathrm{ml}$ sample of blood was drawn as a blank for the propranolol assay.

Blood pressure and pulse rate were recorded supine and erect (after lying for three minutes and standing for one minute) and the forced expiratory volume in one second $\left(\mathrm{FEV}_{1}\right)$ measured. The subjects then inserted a commercially available tablet of propranolol (Inderal) $80 \mathrm{mg}$ as far as possible into the vagina with a pessary introducer. Blood pressure, pulse rate, and $\mathrm{FEV}_{1}$ were recorded at 30

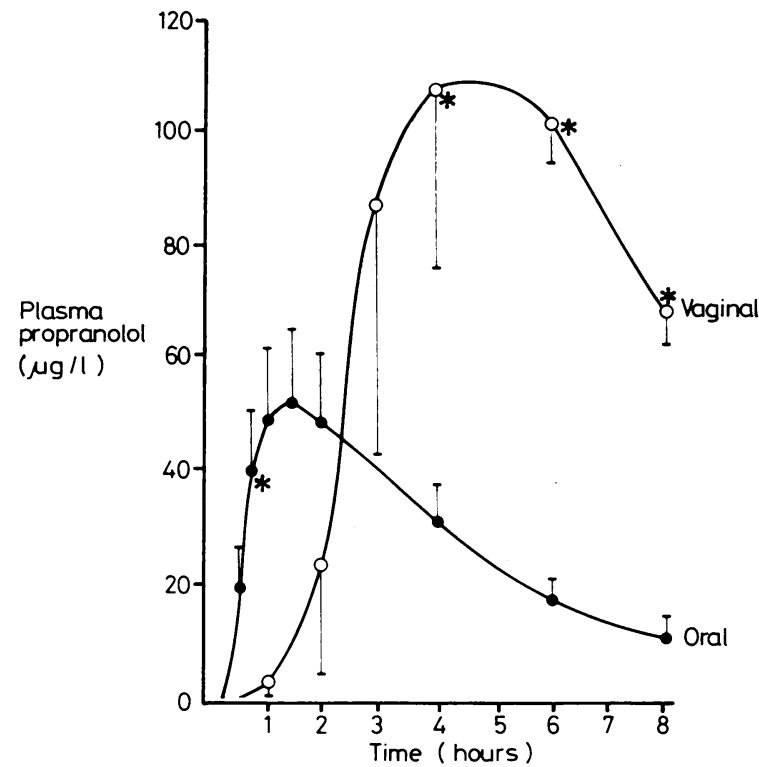

Plasma propranolol concentrations after administration of $80 \mathrm{mg}$ per vaginam and by mouth. Data from four subjects. Points are means. Bars are SEM.

${ }^{*} \mathrm{p}<0.05$.

minutes and at one, two, three, four, six, and eight hours after insertion of propranolol. Further $6 \mathrm{ml}$ blood samples were also taken at these times. Subjects were freely mobile in the study room between observations. They were asked to comment on irritation and any change of sensation in the vagina. On a different day four of the six subjects received $80 \mathrm{mg}$ propranolol by mouth after an overnight fast. Blood samples were taken before and at 15,30 , and 45 minutes and one, two, four, six, and eight hours after ingesting the tablet.

Plasma samples were stored at $-22^{\circ} \mathrm{C}$ until assayed and propranolol concentrations estimated by a sensitive high performance liquid chromatographic method ${ }^{6}$ capable of detecting concentrations of 2.5 $\mu \mathrm{g} / 1$, at which the coefficient of variation was $7 \cdot 2 \%$. Paired $t$ tests were used to analyse the clinical measurements, which were compared with the observations before propranolol was administered, and on the maximal concentrations, area under the concentration-time curve, and time to peak concentration. Some of the subjects did not have detectable concentrations of propranolol in their plasma 30 minutes after placement of the tablets in the vagina, so that paired $t$ tests were performed only on the data derived from later sampling times. The study was approved by the Charterhouse Clinic ethical committee. 


\section{Results}

All subjects completed the study. None complained of vaginal irritation or other symptoms, and vaginal sensation was unaffected. No postural symptoms, breathlessness, or wheezing were noticed.

Blood pressure and lung function-Supine and erect systolic blood pressures fell after the insertion of propranolol when compared with baseline values, the falls being statistically significant $(p<0.05)$ at two, four, six, and eight hours compared with baseline for supine blood pressure and at eight hours for the standing position compared with baseline (table I). Supine and erect diastolic blood pressures were unaffected. Both supine and erect pulse rates and the $F E V_{1}$ also fell (table I), the fall in supine pulse rate being significant $(p<0.05)$ at two to eight hours, in standing pulse rate at 30 minutes and six and eight hours, and in $\mathrm{FEV}_{1}$ at one, two, four, and eight hours after propranolol per vaginam.

Plasma propranolol concentrations-Propranolol concentrations in the concentrations may reflect delay in the dissolution of the tablet and absorption of propranolol.

There were small reductions in blood pressure, pulse rate, $c$ and $\mathrm{FEV}_{1}$, which did not cause any symptomatic side effects in $\widehat{\widehat{O}}$ the volunteers. The reductions in blood pressure and pulse rate $\overline{\bar{J}}$ might have resulted from acclimatisation to the study, but the $D$ reduction in $\mathrm{FEV}_{1}$ was probably a drug related effect. Although \& none of our subjects suffered any symptomatic side effects, TI probably in an unscreened population some would develop bronchospasm if treated with the same dose via the vaginal route.

D-Propranolol is as effective as DL-propranolol in inhibiting human sperm motility in vitro ${ }^{38}$ but almost devoid of beta receptor blocking properties ${ }^{9}$; hence further investigations on the contraceptive effects of propranolol should probably be conducted

TABLE I-Effect of propranolol $80 \mathrm{mg}$ inserted into the vagina on blood pressure, pulse, and forced expiratory volume in one second $\left(F E V_{1}\right)$ in all six patients. Values are means ( $E M$ in parentheses)

\begin{tabular}{|c|c|c|c|c|c|}
\hline \multirow[b]{2}{*}{ Time $(h)$} & \multicolumn{2}{|c|}{ Blood pressure (mm $\mathrm{Hg}$ ) } & \multicolumn{2}{|c|}{ Pulse (beats/min) } & \multirow[b]{2}{*}{$\mathrm{FEV}_{1}(1)$} \\
\hline & Supine & Erect & Supine & Erect & \\
\hline $\begin{array}{l}0 \\
1 \\
\vdots \\
\overline{1} \\
2 \\
3 \\
4 \\
6 \\
8 \\
8\end{array}$ & 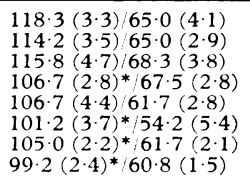 & 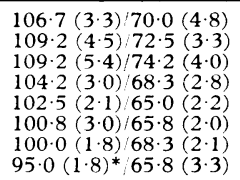 & $\begin{array}{l}74 \cdot 8(2 \cdot 8) \\
69 \cdot 0(1 \cdot 1) \\
67 \cdot 0(3 \cdot 1) \\
63 \cdot 7(1 \cdot 8)^{*} \\
65 \cdot 0(3 \cdot 5)^{*} \\
65 \cdot 7(2 \cdot 0)^{*} \\
64 \cdot 8(2 \cdot 7)^{*} \\
62 \cdot 3(2 \cdot 4)^{*}\end{array}$ & $\begin{array}{l}88 \cdot 2(3 \cdot 3) \\
81 \cdot 3(2 \cdot 7)^{*} \\
79 \cdot 7(2 \cdot 9) \\
70 \cdot 7(3 \cdot 5) \\
71 \cdot 5(6 \cdot 9) \\
69 \cdot 3(2 \cdot 9) \\
68 \cdot 3(2 \cdot 4)^{*} \\
65 \cdot 3(3 \cdot 7)^{*}\end{array}$ & $\begin{array}{l}3.2(0.22) \\
3.2(0.27) \\
3.0(0.22)^{*} \\
3 \cdot 1(0.23)^{*} \\
3.0(0 \cdot 23) \\
3.1(0 \cdot 18)^{*} \\
3.0(0.23) \\
2.91(0 \cdot 21)^{*}\end{array}$ \\
\hline
\end{tabular}

$* \mathrm{p} \cdot 0 \cdot 05$

plasma were higher after vaginal administration than after oral administration (fig). After vaginal administration the drug appeared in detectable concentrations in the plasma after one hour, reaching a maximal concentration at four hours after insertion. At eight hours there was still detectable propranolol in the plasma of all subjects. Data from four subjects given $80 \mathrm{mg}$ propranolol by mouth showed that there was more rapid absorption from the gastrointestinal tract with detectable concentrations in the blood at 30 minutes, reaching a peak 90 minutes after administration. Table II summarises the pharmacokinetic data.

TABLE II-Pharmacokinetic data from vaginal and oral administration of propranolol $80 \mathrm{mg}$ in four subjects. Values are means (SEM in parentheses) [Data from all six subjects studied given in square brackets]

\begin{tabular}{lll}
\hline & Vaginal route & Oral routc \\
\hline Lag time (h) & $2 \cdot 2(0 \cdot 38)[2 \cdot 1(0 \cdot 36)]$ & $0 \cdot 38(0 \cdot 01)^{*}$ \\
Absorption half life (h) & $0 \cdot 80(0 \cdot 2)[0 \cdot 86(0 \cdot 15)]$ & $0 \cdot 31(0 \cdot 04)$ \\
Area under curve $0-\infty(u g .1 \mathrm{~h})$ & $987 \cdot 2(145 \cdot 2)[929 \cdot 8(133 \cdot 2)]$ & $288 \cdot 1(62 \cdot 6)^{*}$ \\
Elimination half life (h) & $4 \cdot 6(0 \cdot 88)[4 \cdot 1(0.65)]$ & $4 \cdot 0(0 \cdot 78)$ \\
Time to peak (h) & $4 \cdot 6(0 \cdot 71)[4 \cdot 5(0 \cdot 49))$ & $1 \cdot 6(0 \cdot 16)^{*}$ \\
Maximal concentration $\mu(\mathrm{g} \mathrm{l})$ & $112 \cdot 0(27 \cdot 9)[106 \cdot 0(19 \cdot 3)]$ & $52 \cdot 2(14 \cdot 3)^{*}$ \\
\hline
\end{tabular}

*p. 0.05

Lag time = delay between drug administration and beginning of absorption. Absorption half life = time for $50^{\prime \prime}$ of drug to be absorbed. Elimination half life =

time for plasma concentration to fall by 50 . Time to peak = delay between

\section{Discussion}

The extensive absorption of drugs from the vagina is well documented. ' In this study the systemic bioavailability of propranolol was greater from the vagina than from the gastrointestinal tract. The greater area under the curve achieved after vaginal administration probably reflects the lack of first pass hepatic biotransformation. Drugs inserted into the vagina show a smaller first pass effect than when taken by mouth, since blood from the vagina enters the systemic circulation directly without passing through the liver. The delay in reaching peak plasma with the dextro isomer. The tolerability of the vagina to drugs and safety of this form ${ }^{110}$ of administration are difficult to predict from animal models, and thus further studies in women of reproductive age are required in order to evaluate the applications of propranolol as a vaginal contraceptive.

We acknowledge support from Family Health International and the Peel Medical Research Trust.

\section{References}

${ }^{1}$ Hahn DW, Homm RE, McKenzie BE. Preclinical evaluation of new vaginal contraception. In : Zatuchini GI, Sobrero AJ, Speidel JJ, Sciarra JJ, eds. Vaginal contraception-new developments. Hagerstown: Harper and Row, 1979:234-46.

2 Peterson RN, Freund M. Effects of $(\mathrm{H}+),(\mathrm{Na}),(\mathrm{K})$ and certain membraneactive drugs on glycolysis, motility and ATP synthesis by human spermatozoa. Biol Reprod 1973;8:350-7.

${ }^{3}$ Hong CY, Chaput de Saintonge DM, Turner P. Inhibitory action of procaine, $(\because)$ propranolol and $(-)$ propranolol on human sperm motility: antagonism by caffeine. Br $\mathcal{f}$ Clin Pharmacol 1981;12:751-3.

- Zipper J, Bruzzone ME, Angelo S, Munoz V, Wheeler RG. Effect of topically applied adrenergic blockers on fertility. Int 7 Fertil 1982;27: $242-5$.

${ }^{5}$ Zipper J, Wheeler R, Potts DM, Rivera M. Propranolol as a novel, N effective spermicide: preliminary findings. $\mathrm{Br}$ Med $\mathcal{f}$ (in press).

- Holt DW, Bhamra RK, Flanagan RJ, Tynan MJ. A rapid high-performance liquid chromotographic method for the measurement of propranolol in $\widetilde{\sigma}$ small samples of blood, plasma or serum at concentrations attained $\bullet$ during therapy. Proceedings of the World Congress of paediatric and laboratory medicine. Jerusalem: 1980:192.

- Benziger DP, Edelson J. Absorption from the vagina. Drug Metab Rev 1983;14:137-68.

'Peterson RN, Freund M. The inhibition of the motility of human sper matozoa by various pharmacologic agents. Biol Reprod $1975 ; \mathbf{1 3}: 552-6$.

'Barrett AM, Cullum V. The biological properties of the optical isomers of propranolol and their effects on cardiac arrhythmias. Br $\mathcal{F}$ Pharmc col $1968 ; 34: 43-55$.

${ }^{10}$ Eckstein P, Jackson MCN, Millman N, Sobrero AJ. Comparison of vaginal tolerance tests of spermicidal preparations in rabbits and monkeys f Reprod Fertil $1969 ; 20: 85-93$. 蒿 .

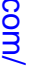
O .

$$
\text { 軩 }
$$

